\title{
Editorial: Equity and equality in education
}

\author{
Stephen Roche
}

Published online: 9 May 2013

(C) Springer Science+Business Media Dordrecht 2013

The first decade of this century saw a dramatic increase in the global demand for tertiary education; between 2000 and 2007 alone, it increased from approximately 100 million to over 150 million enrolments. Nowhere has this demand increased more than in sub-Saharan Africa, where third-level enrolment rates grew by 10 per cent per annum between 2000 and 2005. Yet, whereas in most other regions of the world the private sector has expanded to meet part of the demand, and many public universities in Europe and North America have increased their reliance on private funding, higher education in Africa is almost exclusively funded by the state, despite the fact that the overwhelming majority of Africans will never benefit from this investment (UIS 2009). This creates a dilemma for public education policy. Should governments invest in a rapidly growing sector even though it still serves a narrow segment of the population, moreover that with the highest income?

The authors of our first article in this issue, Hadrat Yusif, Ishak Yussof and Zulkifly Osman, take a critical look at tertiary education in Ghana, where despite high state investment ( 20 per cent of the education budget), participation in higher education remains low (6 per cent of the overall population, and just 4 per cent of women). The authors employ a binary logistic regression model to determine the equity of access to public universities in Ghana. They conducted a quantitative study of 1,129 senior high school students at ten schools, considering a number of variables likely to influence participation, including family size and structure, the students' own aspirations, parental education and parental occupation, and school characteristics. Their findings corroborate those of previous studies, showing that access to higher education in sub-Saharan Africa is largely confined to students with wealthier and more educated parents, thus perpetuating a cycle of exclusion. The authors recommend greater public investment in poorly resourced senior high

\footnotetext{
S. Roche $(\square)$

UNESCO Institute for Lifelong Learning, Hamburg, Germany

e-mail: s.roche@unesco.org
} 
schools and an extension of affirmative policies to encourage and support admissions from less endowed schools.

The study of university admission in Ghana reminds us that access to education is influenced by many competing and complementary factors. Even gifted students from poor socio-economic backgrounds need to overcome a variety of hurdles both implicit and explicit - in order to climb the educational ladder. Not the least of these is language. Today, not a single country in sub-Saharan Africa uses an African language as its main language of instruction in secondary education, and in most, colonial languages are preferred even in primary education (Ouane and Glanz 2011). This flies in the face of research findings and common sense alike, as students learn best when taught in a language in which both they and their teachers are proficient. Martha A. S. Qorro examines this issue in the particular context of Tanzania, which pioneered native-language instruction under its first president Julius Nyerere, based on a core belief in the centrality of education to nationbuilding. The author first presents findings from 18 different studies of language of instruction (LOI) in Tanzania since 1974, then asks why research results showing that children learn better in Kiswahili than in English have not been acted upon. The answers go to the heart of the debate on language policy, revealing the vested interests and forces that influence the choice of LOI. The author concludes with a searing critique of Tanzania's English-language policy, both from pedagogical and ethical perspectives: "it is pedagogically unsound to instruct students in this language which is incomprehensible to most ... [and] ... it is unethical and immoral to (pretend to) 'teach' students in an incomprehensible language, and then examine and judge them as having 'failed' when they struggle in exams."

Our third article is also concerned with the issue of equity in education; in this case, girls' access to primary education in Yemen. At first glance, the situation in Yemen is not encouraging; it is one of the world's poorest countries, with a female adult literacy rate of 39 per cent. However, it was identified by UNESCO as a country that had achieved "rapid progress towards gender parity from a low base", having significantly increased both general enrolment and gender parity since 1999 (UNESCO 2010). Much of this progress can be attributed to government policies, starting with compulsory and free basic education (grades 1-9) in the early 1990s, and followed by a school building programme, increased consultation with communities, and introduction of more female teachers to rural schools. The authors of our article, Takako Yuki, Keiko Mizuno, Keiichi Ogawa and Sakai Mihoko, analysed the results of the first phase of the Broadening Regional Initiative for Developing Girls' Education (BRIDGE) project that was developed and run by the Japan International Cooperation Agency (JICA). Recognising community and parental involvement as a key factor in increasing the enrolment of girls, the project piloted a community participation model, involving the formation of parents' councils in the 53 participating schools. These councils help to manage and allocate government grants to increase female enrolment. The authors found that the BRIDGE model was highly effective not only in increasing enrolment, but also in improving the school environment, nurturing relationships between schools and communities, and developing more positive attitudes to girls' schooling among school management and community members. As the study included data gathered 
two years after the conclusion of the project, the authors were able to draw conclusions on the medium-term impact. In this regard, they inferred that continuous long-term guidance and monitoring were vital in maintaining progress in gender parity.

While the world's poorest countries have been working to increase the participation of girls in education, many of the wealthiest countries are concerned that girls now outperform boys at school and outnumber them at university. Starting in the 1990s, several studies of school performance in Europe and North America pointed to a widening gender gap in favour of girls. Several governments commissioned studies to investigate this phenomenon, and to recommend appropriate responses. Our article by Geert Driessen and Annemarie van Langen is based on one such study, commissioned by the government of the Netherlands, in which the authors investigated differences in school performance (primary and early secondary) between boys and girls. Their quantitative data analysis encompassed large-scale cohort studies and national population databases, as well as national and international school achievement studies, including PIRLS and PISA. ${ }^{1}$ The authors found that there was little evidence of an aggregate difference in cognitive competencies between boys and girls. Rather, girls outperformed boys in certain competencies (such as reading and languages), while boys surpassed girls in others (e.g., mathematics and science). The most significant divergence between boys and girls was in non-cognitive competencies, such as behaviour and attitude, with girls outscoring boys in most of the domains tested (e.g., well-being, social behaviour, work attitude and task orientation). Interestingly, boys scored considerably higher on competition and self-efficacy (confidence in their own abilities). Major differences were also identified in "school career" characteristics, with girls far less likely to repeat classes or require special-needs tuition, and more likely to reach the highest level of secondary school (university track). The authors also identified a "horizontal" disparity between the sexes; namely, an inequality of gender distribution between the sectors and courses chosen in the later stages of lower secondary education, with boys opting disproportionately for science and technology-related subjects and girls for more socially oriented subjects. Given the current job market in the Netherlands, the authors regard this disparity as being chiefly to the disadvantage of girls. While the study confirms many of the findings produced in similar contexts, it does not indicate where this trend is likely to lead.

At the UNESCO Institute for Lifelong Learning we tend to spend a lot more time thinking about teaching people to read than considering how that skill, once acquired, is used. The study by Peter Broeder and Mia Stokmans looks at what motivates adolescents to read for pleasure. While reading behaviour of adolescents is a frequent object of research, most studies in this field are restricted to a single country, and focus mainly on the instrumental benefits of reading. Our authors' sample comprises a total of 2,173 pupils from schools in the Netherlands, Beijing and Cape Town; three regions that differ greatly, both in terms of reading culture

\footnotetext{
1 PIRLS (Progress in International Reading Literacy Study) and PISA (Programme for International Student Assessment) are large-scale international comparative studies of student performance, conducted by the International Association for the Evaluation of Educational Achievement (IEA) and the Organisation for Economic Co-operation and Development (OECD) respectively.
} 
and the amenities available for reading. They focus on the antecedents of reading behaviour - which elements contribute to the intention to read - applying Icek Ajzen's Theory of Planned Behaviour (TPB). Generally speaking, TPB assumes that people will follow a given behaviour if they believe that the advantages of success will outweigh the disadvantages of failure (Ajzen 1985). In the case of adolescent reading behaviour, advantages may include the pleasure derived from reading and the approval of parents and teachers; disadvantages may include peer disapproval and parental pressure. The authors adapted the TPB model to identify three principal determinants of reading behaviour: reading attitude, social pressure to read, and perceived behavioural control (self-assessed reading proficiency and the perception of the appropriateness of the book supply). By selecting these, rather than more conventional variables, such as educational level, school climate and socioeconomic background, the authors were able to compare reading behaviour in vastly different social and cultural contexts. This study suggests that the motivation to read, based on attitude and social pressure, can only be converted into actual reading behaviour if an adolescent has both the competences and the opportunities to read. The findings indicate that the most important determinants are the subjective pleasure derived from reading, the implicit norm of family and friends, the attractiveness of the available choice of books, and the perceived reading proficiency.

"To read or not to read" is a question not only posed by adolescents; it is also a dilemma facing new parents. Starting with Dr. Spock's Common Sense Book of Baby and Child Care (Spock 1946), parenting guides have assumed a place in postWar Europe and North America previously occupied by traditional knowledge, passed down from grandparents to parents. Parenting books now fill entire bookstore aisles, and new parents can feel torn between different theories and approaches. These may be crudely divided into two groups - traditionalist and progressive. Each camp tends to blame the other for the ills of society and, indeed, the subject of parenting might well be added to the twin unmentionables of polite society, politics and religion. Democratic parenting undoubtedly belongs to the progressive category of parenting approaches, involving the application of democratic values to parent-child relations, advocating sharing power with children and including them in family decision-making. Our final article, by Shlomit Oryan and John Gastil, presents a textual analysis of two approaches to democratic parenting, the Adlerian and the parent effectiveness models, as reflected in two popular and influential books, Children: The Challenge by Rudolf Dreikurs (1964) and Parent Effectiveness Training by Thomas Gordon (1975). This qualitative study examines the paradoxes inherent in these two theories, in particular the challenges in reconciling parental guidance and authority with respect for a child's democratic will. They find that both approaches, while championing the idea of democracy in the family, tend to manipulate the child to make decisions that comply with the parents' wishes, thereby enforcing a non-democratic order. As an alternative, the authors propose a "guardianship" approach that aims to gradually prepare children for the responsibilities of participation in family decision-making, and ultimately for autonomous democratic citizenship. 


\section{References}

Ajzen, I. (1985). From intentions to actions: A theory of planned behavior. In J. Kuhl \& J. Beckman (Eds.), Action-control: From cognition to behavior (pp. 11-39). Heidelberg: Springer.

Dreikurs, R. (1964). Children: The challenge. New York: Hawthorn Books.

Gordon, T. (1975). Parent effectiveness training. New York: Plume.

Ouane, A., \& Glanz, C. (Eds.). (2011). Optimising learning, education and publishing in Africa: The language factor. A review and analysis of theory and practice in mother-tongue and bilingual education in Sub-Saharan Africa. Hamburg/Tunis: UIL/ADEA.

Spock, B. (1946). Common sense book of baby and child care. New York: Duell, Sloan and Pearce.

UIS (UNESCO Institute for Statistics) (2009). Global education digest 2009. Montreal: UIS.

UNESCO (2010). EFA global monitoring report: Reaching the marginalized. Paris: UNESCO. 